\title{
Article \\ Fault Detecting Accuracy of Mechanical Damages in Rolling Bearings
}

\author{
Karolina Kudelina ${ }^{1, *(\mathbb{C})}$, Tatjana Baraškova ${ }^{2}$, Veroonika Shirokova ${ }^{2}$, Toomas Vaimann ${ }^{1}{ }^{1}$ and Anton Rassõlkin ${ }^{1}$ (D) \\ 1 Department of Electrical Power Engineering and Mechatronics, Tallinn University of Technology, \\ 19086 Tallinn, Estonia; toomas.vaimann@taltech.ee (T.V.); anton.rassolkin@taltech.ee (A.R.) \\ 2 Mechanical Engineering and Energy Technology Processes Control Work Group, Virumaa College, \\ 30322 Kohtla-Järve, Estonia; tatjana.baraskova@taltech.ee (T.B.); veroonika.shirokova@taltech.ee (V.S.) \\ * Correspondence: karolina.kudelina@taltech.ee
}

check for

updates

Citation: Kudelina, K.; Baraškova, T.; Shirokova, V.; Vaimann, T.; Rassõlkin, A. Fault Detecting Accuracy of Mechanical Damages in Rolling Bearings. Machines 2022, 10, 86. https://doi.org/10.3390/ machines 10020086

Academic Editors: Alejandro Gómez Yepes and Hui Ma

Received: 23 December 2021

Accepted: 23 January 2022

Published: 25 January 2022

Publisher's Note: MDPI stays neutral with regard to jurisdictional claims in published maps and institutional affiliations.

Copyright: (C) 2022 by the authors. Licensee MDPI, Basel, Switzerland. This article is an open access article distributed under the terms and conditions of the Creative Commons Attribution (CC BY) license (https:// creativecommons.org/licenses/by/ $4.0 /)$.

\begin{abstract}
Electrical machines are to face different challenging factors during operation, such as high unexpected or excessive loads, unusual properties of the working environment, or intense fluctuations in rotation speed. Therefore, maintenance questions and predicting the accuracy of an equipment's condition have great importance. This study is based on the theory of vibration reliability. This article introduces the most common faults of bearings in electrical machines and discusses their diagnostic possibilities. Experimental setup, as well as studied bearing failures, are described. The accuracy of conducted experiments is introduced.
\end{abstract}

Keywords: ball bearings; fault diagnosis; vibration measurement; condition monitoring; failure detection; reliability

\section{Introduction}

Condition monitoring and failure prediction of the equipment are crucial due to their wide usage in different applications. Considering options for servicing critical technical systems, creating the possibility of periodic measurements for all machines seems inevitable. However, proper assembly and careful maintenance of the equipment makes it possible to reduce the number of scheduled checks of the devices, including measurement of the vibration level up to two or three times a year. It is also related to security issues and resource savings. Therefore, the creation of an effective condition monitoring system would ensure the reliability of technical resources and the quality of service.

If the vibration frequency is not constant, fractional derivatives are used. These derivatives demonstrate effectively use of vibration acceleration changes and vibration intensity. The derivative order can be any actual number. The intensity of the vibration acceleration change is estimated by the frequency spectrum of the vibration power [1]. During the processing of signals, which inform on the level and balance of vibration, accuracy becomes critical, and, therefore, the ISO 16063 series of standards are used [2]. In case of the absence of a tachometer (conditions for performing repeated multiple measurements and with a rapidly changing speed of rotation of the drive shaft), the diagnostic method is described in [3].

Many studies in literature are related to the described problems. Authors in [4] present an analysis of feature extraction methods in vibration-based condition monitoring for low-speed slew bearing. In [5], authors introduce a study of fault diagnosis of a low-speed bearing based on acoustic emission signal and multi-class relevance vector machine. In [6], an optimization method was applied to diagnose rolling bearing malfunctions, such as an optimization-based improved kernel novel method based on machine learning. At the same time, reducing the dimension of output values makes sense when assessing signs of machine part malfunctions, although it is difficult to determine the main influencing factors. Impressive findings on the diagnostic analysis of acceleration signals from rolling element 
bearings are presented in [7]. Analyzing the envelope makes it possible to strongly estimate masking signals from gear elements in non-stationary conditions. Authors in [8] apply the basic calculations of the uncertainty of measurement results during vibration transmission, but do not estimate the standard uncertainty. Attention is paid to the assessment accuracy of the rolling bearings state in [9]. One of the approaches of real-time monitoring mode is proposed, but it is not proven that all the requirements for the accuracy of the assessment are met. The application of numerical modeling for applied studies of the state of mechanical systems is presented in [10]. Good results were obtained in the interference suppression mode. An assessment of the accuracy of monitoring the technical condition of objects is given in [11]. The industry has experimentally confirmed that vibration sensors increase the accuracy of measurements. The article [12] presents an interesting algorithm for predicting the state of machining tools during the processing of parts. The mathematical modeling problems are solved in [13] by constructing multifactorial mathematical models for turbine units. The article presents modern methods for wear monitoring of turning tools and the possibility of using the phase chronometer diagnostic method to assess tool wear [14]. Authors in [15] discuss challenges and perspectives of data-driven fault diagnosis for traction systems in high-speed trains.

The reliability of equipment that operates in heavy conditions is based mainly on the analysis of spontaneous emissions of oscillatory processes and on the study of damage accumulation. The initial distribution of defects, operating conditions, and the mechanical system's interaction with the environment leads to accidental failures. It is necessary to describe the behavior of a mechanical system with a high degree of accuracy. A dynamic model of a closed electric drive with a measuring system configured for a monitoring mode is considered as a mechanical system. The measuring system must meet the Certificate in Investment Performance Measurement of Mutual Recognition Arrangement (CIPM MRA) conditions. Thus, the measurement system must be intelligent and time-bound. The SI-based data exchange system standard introduced metrology into digital format. All data are collected and processed according to this unit system.

This article is organized as follows. In Section 2, the most common faults of bearings in electrical machines are introduced and their diagnostic possibilities are discussed. Section 3 presents experiments done in the framework of the given study describing the test bench and studied bearing failures. In Section 4, the results of the conducted experiments are presented and their accuracy is discussed.

\section{Bearing Faults}

According to statistics, $50 \%$ of all failures in electrical machines are referred to as mechanical faults causing additional noise and vibrations and leading to the total breakdown of the device [16]. Bearings are the critical elements of a rotating machine. At the same time, bearing faults carry the highest portion of mechanical damages. The manufacturing of bearings is to be carried out under stringently defined requirements. However, the actual lifespan of the bearing is much lower than it is supposed to be due to different forces affecting it during operation, such as unexpected overload, insufficient lubrication, and improper bearing installation [17]. As electrical machines operate in other conditions, bearings can be prone to many faults and damages. The reasons for these failures are different environmental or manufacturing factors.

\subsection{Mechanical Damages}

Most bearing faults are related to mechanical damages, which can occur due to manufacturing failures or unexpected conditions during motor operation. Usually, these mechanical damages are referred to as inner and outer rings, cages, or rolling elements. An example of a faulty bearing cage is shown in Figure 1. 


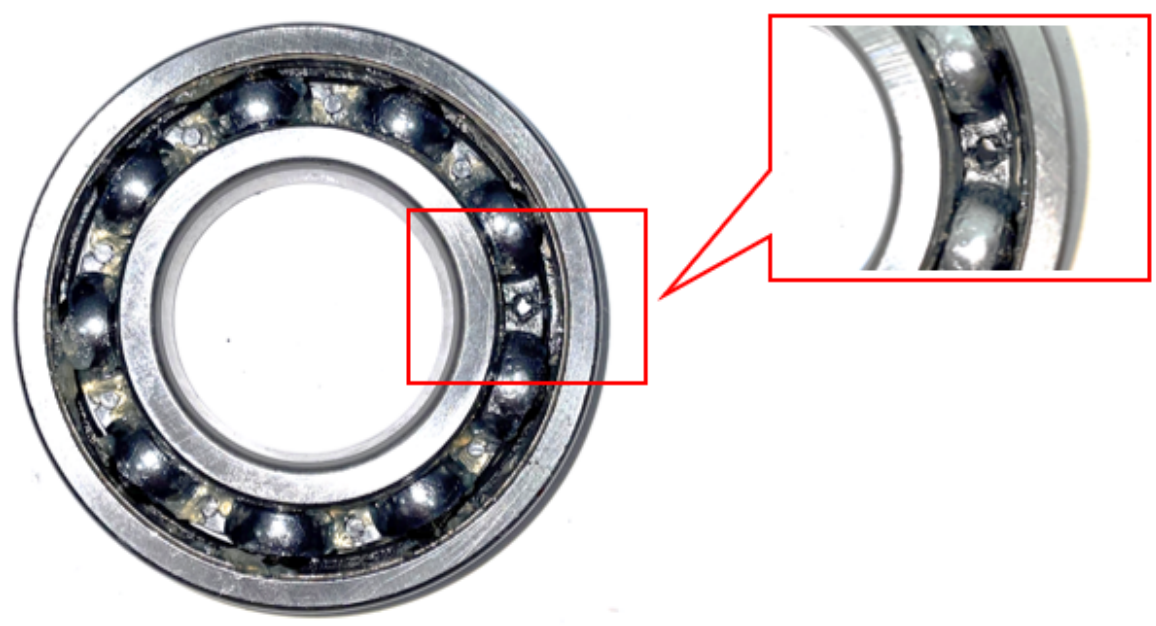

Figure 1. Damaged cage in rolling bearing.

These mechanical damages can also be caused by an incorrect manufacturing or mounting process, improper design, misalignment of bearing rings, or unequal proportions of rolling elements. Before placing the bearing, it is mandatory to check for manufacturing faults: general appearance, rotational ease, and clearances of technical documentation requirements. Usually, open-type approaches are to be checked for contamination, corrosion, and cage condition. For sealed-type bearings, cages should also be checked to prevent possible damages.

\subsection{Material Fatigue}

Material fatigue is usually caused by continuous loads that crack the bearing's surface. If external forces are applied to the bearing rings, the strength of the material decreases, causing it to crack. Over time, cracking progresses, and, eventually, the bearing becomes unsuitable for further exploitation. The bearing's durability is measured by the number of revolutions that the bearing makes before the first signs of material fatigue become noticeable on rings and rolling bodies [18]. An example of bearing material fatigue is shown in Figure 2.

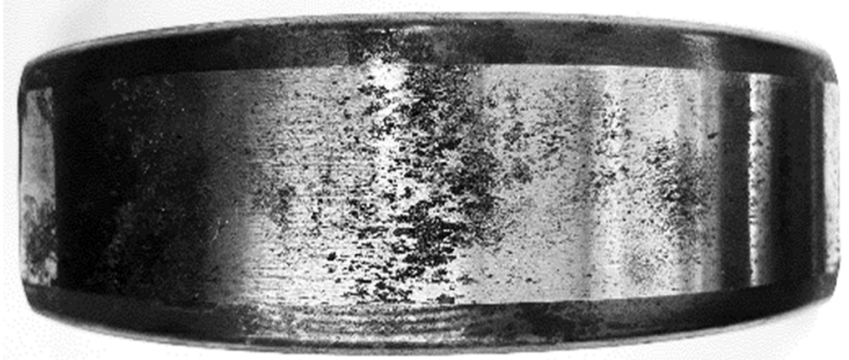

Figure 2. Material fatigue of a rolling bearing.

Continuous overload, poorly maintained, and contaminated surfaces-all these factors inevitably lead to material fatigue. This phenomenon, its time occurrence, and developing process largely depend on the magnitude of the machine's applicable load and rotational speed. Initially, microcracks appear in the subsurface. By process development, the surface of the bearing begins to crack on a larger surface and becomes rough. In this case, additional noise and vibration can be detected. In addition, the operating temperature of the bearing increases. The bearing should be regularly checked and well lubricated to prevent this failure. 


\subsection{Ambient Contamination}

When humid air enters the bearing, it tears lubricant properties at certain points of an increased load on rings. In addition, lubricants can become polluted by water or other chemical substances. As lubricant properties are deteriorated, bearing corrosion appears. Corrosion is a process between material and environment that results in material dissolution. Proper lubrication is one of the bearing operating conditions that determines its durability. Rightly selected lubricant provides a thin oil layer, which helps to soften the impact of rolling elements against bearing rings and cages.

Moreover, the lubricant prevents the bearing from premature wear and corrosion. Improper lubrication can be referred to as an insufficiently as well as excessively greased bearing. Insufficient lubrication causes friction and crack progression, while an overly greased bearing results in the shaft slipping and leads to structural damage. An example of bearing corrosion is shown in Figure 3.

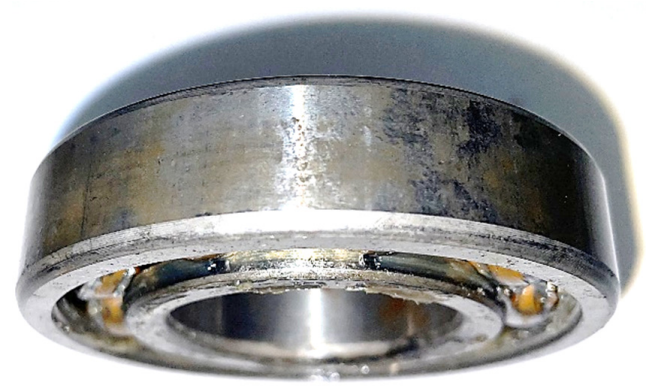

Figure 3. Corroded surface of a rolling bearing.

Bearings can also be polluted by dust, sand, and other abrasive particles. This pollution leads to structural damages of the bearing (e.g., scratches, cracks) and produces significant dents when the rolling element rolls the shaving into the rings. The main reason for these damages is the wrongly selected bearing cage, preventing such particles from entering the bearing. As a preventative factor, corrosion-resistant lubricants can be used. Moreover, it is vital to keep the mounting process clean and not to use contaminated greases.

\subsection{Bearing Currents}

Bearings are often affected by shaft currents. If current passes through the bearing, damages will appear on the bearing surfaces. Usually, these failures occur in bearing areas, where the lubricant layer is the thinnest due to the increased load at these points. The most common damages caused by shaft currents are shown in Figure 4. Fluting usually occurs with low voltage and constant rotational speed, where multiple lines occur across bearing rings. At the same time, frosting occurs if the motor operates at varying speeds. Pitting is usually caused by low speed and supplied high-voltage sources. Practically, dull-finish can also be observed, which resembles pitting, but the size of the craters are much smaller.

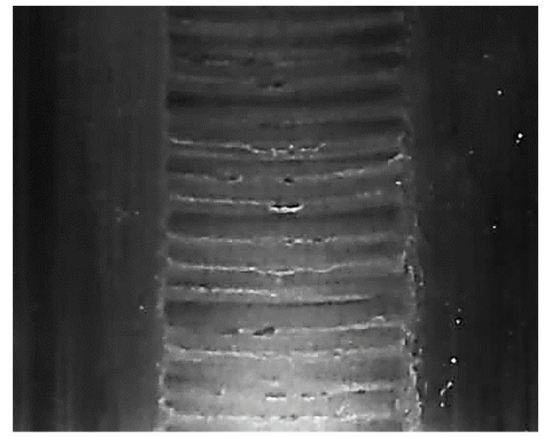

(a)

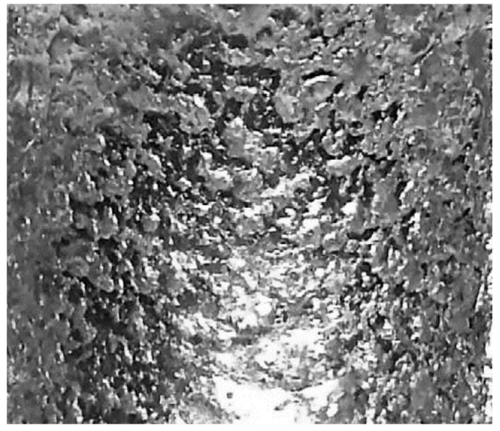

(b)

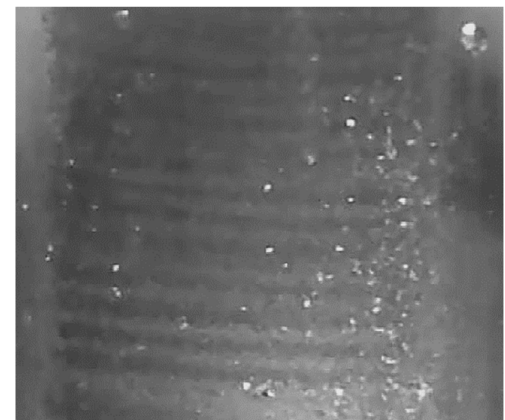

(c)

Figure 4. Faults caused by shaft currents: (a) fluting, (b) frosting, and (c) pitting. 
The first indicator of a possible problem related to shaft currents is lubricant darkening, which oxidizes during sparking caused by electrical discharges, as shown in Figure 5.
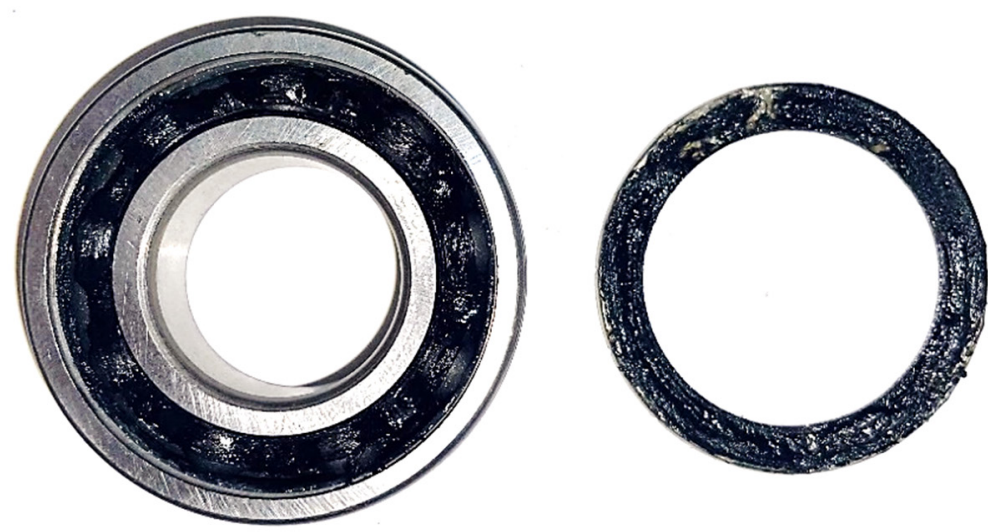

Figure 5. Darkened lubricant.

At the initial stages, these damages are not visible and cannot be detected without disassembling the bearing and searching for microscopic deviations on the bearing rings and rolling elements [19]. By fault development, the damage inflicted on the bearings due to currents differs visually from other bearing damages. For this reason, it is crucial to inspect changes in bearings in all cases during service if there is a reason to suspect the presence of bearing or shaft currents, especially in those cases where bearings are used in larger power class frequency converter-fed electrical machines.

\section{Experiments}

The dynamic model of the electric drive was studied in the torque control mode. Drive composition: a three-phase asynchronous motor C71B-2 with cage rotor, rotary optical encoder with IR-LED, precision ball bearings, grooved ball bearing 6004-2ZR, and belt drive with eccentric belt pulley with a pretension V-belt. The test bench is presented in Figure 6 .

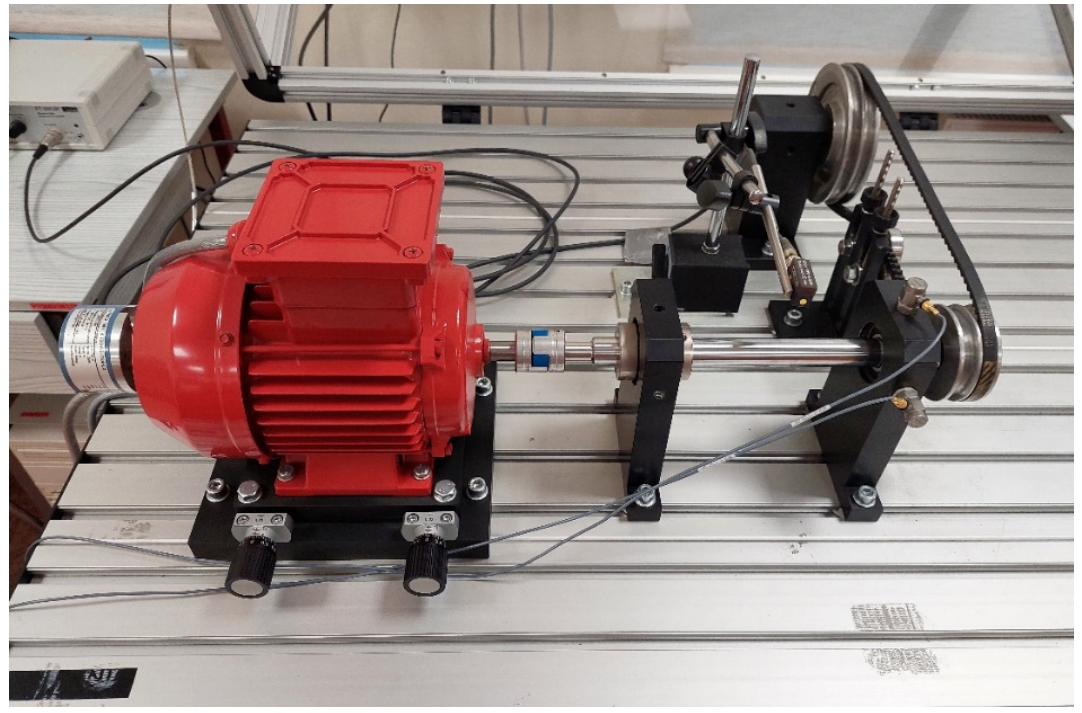

Figure 6. Bearing testing.

The highest speed and the shorter interval between signals made it possible to obtain more accurate metrological support for monitoring the technical condition of a ball radial single-row rolling bearing. As shown in Figure 7, the accelerometer output signal's root mean square (RMS) value was measured. The frequency range and measurement uncer- 
tainty allow you to accurately evaluate the results of comparing different bearing fault signature extractions.

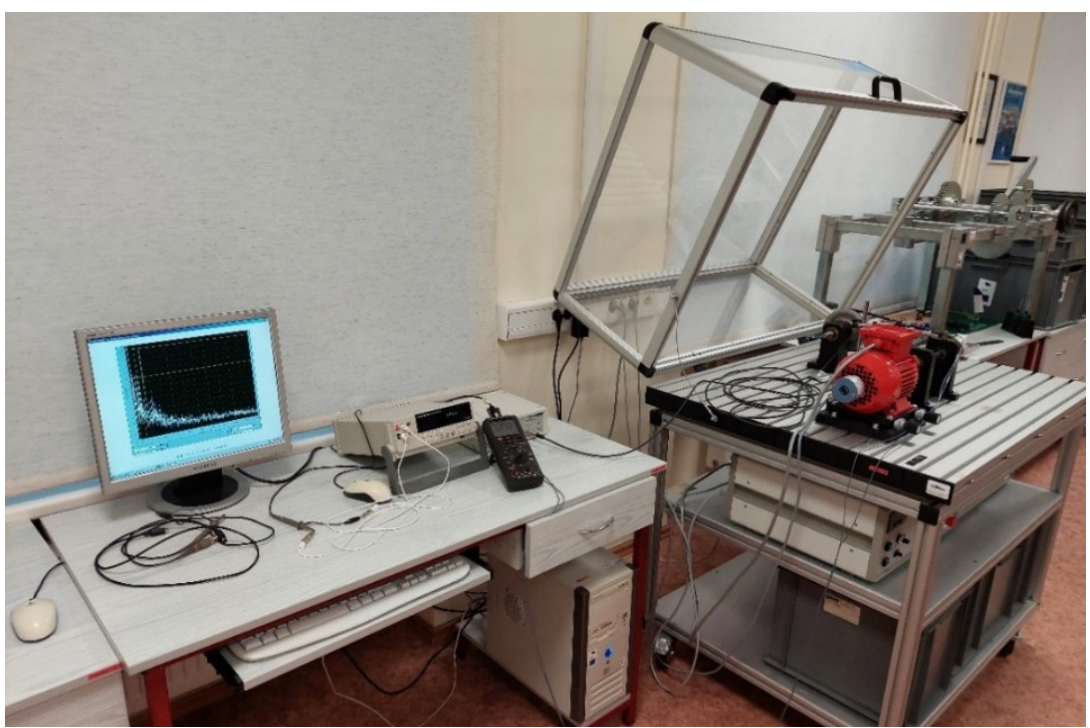

Figure 7. Experimental test bench.

Before the experiment, the belt was pre-tensioned, thereby maintaining the speed of the rotation of the shaft. In the experiment, a vibration stand with the following characteristics was used: a non-linearity of $\pm 1 \%$, measuring range of $\pm 490 \mathrm{~m} / \mathrm{s}^{2}$ or $\pm 50 \mathrm{~g}$; broadband resolution of $3434 \mu \mathrm{m} / \mathrm{s}^{2}$. Small transverse and angular vibrations of the vibration stand table do not significantly affect the measurement results. The deviation of the acceleration amplitude during the measurement process is not more than $0.05 \%$ of the displayed value. The test unit's electronic noise is below the maximum value of the output signal.

Deep groove ball bearings (type 6004 2RS) were used in these experiments. Healthy bearings were studied as well as bearings with additional damages. As shown in Figure 8, the following cases were studied: the healthy bearing, bearing with damaged inner ring, bearing with damaged outer rings, bearing with broken cage, complex bearing damage (damaged outer ring, inner ring, and cage), and bearing with material fatigue.

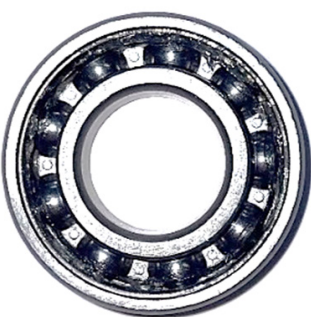

(a)

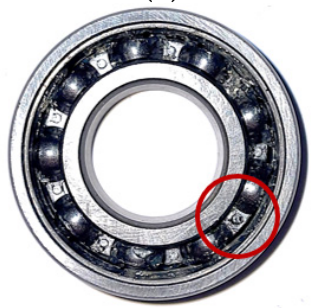

(d)

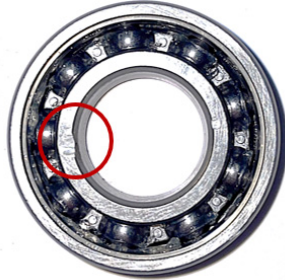

(b)

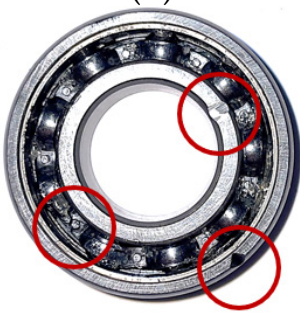

(e)

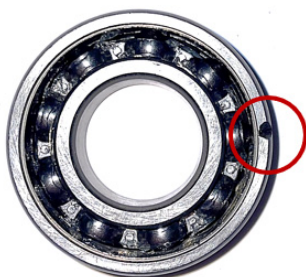

(c)

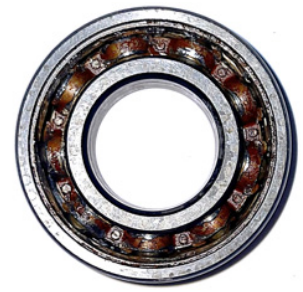

(f)

Figure 8. Studied bearings with different damages: (a) healthy bearing, (b) bearing with damaged inner ring, (c) damaged outer ring, (d) damaged cage, (e) complex damage, and (f) material fatigue. 


\section{Results}

The data exchange should be carried out very quickly. Synchronization of the measurement system was carried out programmatically. The created software was effectively used to detect malfunctions in the drive parts at a low speed. A program was developed for more accurate recording of shock loads at low shaft rotation frequencies that allow recording shock loads in milliseconds. With such a sampling rate of vibration signals, it is challenging to diagnose malfunctions in bearings in belt drives. The shaft rotation frequency was $300 \mathrm{rpm}$ in the experiment, thus the sampling frequency was $5 \mathrm{~Hz}$. Low frequency and accessing a digital voltmeter at every millisecond made it possible to assess the condition of the bearing with great accuracy.

The algorithm is suitable for processing vibration spectra, which will allow continuous instant monitoring in the future. To implement the theoretical foundations of diagnostics, a custom program Lucia was created and written in C++ using the MFC (Microsoft Foundation Classes) library for synchronous monitoring of the state of the drive. MATLAB $2021 b$ without Toolbox application was used only for process visualization. Lucia is aligned with MATLAB 2021b software. There are two options for synchronizing the measurement system's operation: the program makes a measurement request and reads data from the port, setting the print-only mode.

In this way, you can change the data transfer rate and the intervals between data. All parameters can be monitored, and the results of diagnostics of the condition of the drive parts can be evaluated more accurately. The diagnosis of bearings with known malfunctions was carried out. Further, diagnostics of similar bearings with unknown malfunctions were carried out. The measurements are synchronized, as the timestamp of each measure is displayed in milliseconds and ticks. Based on these data, it is possible to estimate the interval between measurements and the data transfer rate. Theoretical values of data transfer rates do not correspond to actual values due to the asynchronous data exchange mode via COM port. The condition-monitoring scheme of using the custom Lucia program is shown in Figure 9.

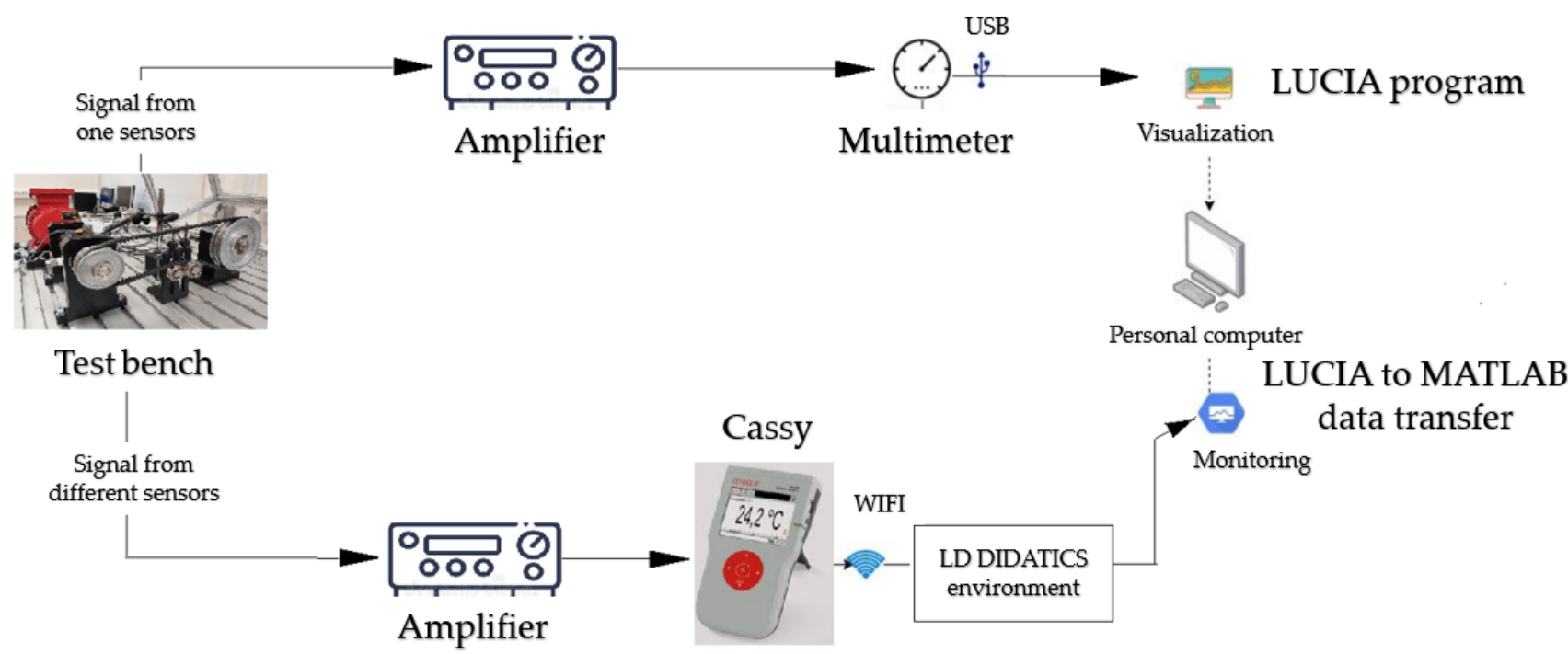

Figure 9. Condition-monitoring scheme of using custom Lucia program.

An alternative approach to the metrological control of the technical condition of rolling bearings is based on a single measurement information format. As an etalon, we use a bearing with a known character of the damage. At the first stage, we establish the ratio between the values of frequencies occurring due to damage in the etalon bearing depending on the speed, considering the measurement uncertainties. At the second stage; we use this information to establish the ratio necessary to assess the condition of a bearing with an unknown nature of damage based on the readings of the measurement system. 
Conducting comparative measurements [20], the value of $F_{s}$, which is the response of a malfunction of the etalon bearing, is compared with the value of $F_{c}$, which is the response of a malfunction of a bearing with unknown damage. As a rule, during the implementation of such measurements, the difference between these values $\Delta=\mathrm{F}_{\mathrm{C}}-\mathrm{F}_{\mathrm{S}}$ is determined. This difference is used to make corrections to the measurement result in the future. In this case, the estimation of measurement uncertainty consists of estimating this difference's uncertainty $\Delta$. The model equation in the case of comparing the results has the form:

$$
\Delta=\left(\mathrm{F}_{\mathrm{C}}+\Delta_{\mathrm{C}}\right)-\left(\mathrm{F}_{\mathrm{S}}+\Delta_{\mathrm{S}}+\theta_{\mathrm{S}}\right)
$$

where $\mathrm{F}_{\mathrm{C}}$ the value associated with the response of a bearing malfunction with unknown damage; $F_{S}$ the value associated with the failure response of the etalon bearing; $\Delta_{S} q u a n t i z a t i o n$ error of the measuring instrument at the first stage of measurements; $\theta_{\mathrm{S}}$ non-excluded systematic error of the measuring instrument; $\Delta_{C}$ - error of quantization of the measuring instrument at the second stage of measurements. The following uncertainties correspond to the listed input values:

- $\quad \mathrm{u}\left(\mathrm{F}_{\mathrm{S}}\right)$-Uncertainty associated with the scattering of readings related to the etalon bearing, and determined statistically when performing multiple measurements;

- $\mathrm{u}\left(\Delta_{\mathrm{S}}\right)$-Uncertainty of quantization of the measuring instrument at the first stage of measurements;

- $\quad \mathrm{u}\left(\theta_{\mathrm{S}}\right)$-The uncertainty of the measuring instrument obtained from the value of its non-excluded systematic error;

- $\quad \mathrm{u}\left(\mathrm{F}_{\mathrm{C}}\right)$-Uncertainty associated with the scattering of readings related to a bearing with an unknown nature of the damage, and determined statistically when performing multiple measurements;

- $\quad \mathrm{u}\left(\Delta_{\mathrm{C}}\right)$-Uncertainty of quantization of the measuring instrument at the second stage of measurements.

As the quantization error of the measuring instrument is the same at the two stages of measurement, it can be ignored. In this case, when processing the measurement results, it is advisable to use the method of reduction [ISO/IEC]. Then, the total standard uncertainty of comparative measurements will be determined by the expression:

$$
\mathrm{u}(\Delta)=\sqrt{\mathrm{u}^{2}\left(\mathrm{~F}_{\mathrm{C}}-\mathrm{F}_{\mathrm{S}}\right)+\mathrm{u}^{2}\left(\theta_{\mathrm{S}}\right)}
$$

where $\mathrm{u}\left(\mathrm{F}_{\mathrm{C}}-\mathrm{F}_{\mathrm{S}}\right)$-is the uncertainty associated with the scattering of the difference in readings at the first and second measurement stages statistically determined. The extended uncertainty of comparative measurements will be equal to:

$$
\mathrm{U}=\mathrm{t}_{0.95}\left\{(\mathrm{n}-1)\left[\frac{\mathrm{u}(\Delta)}{\mathrm{u}\left(\mathrm{F}_{\mathrm{C}}-\mathrm{F}_{\mathrm{S}}\right)}\right]^{4}\right\} \cdot \mathrm{u}(\Delta)
$$

As mentioned, created software is coordinated with the MATLAB r2021b program. The most common envelope analysis method in non-stationary conditions was carried out for a bearing with an expected defect on the inner ring at a shaft rotation speed of 300 revolutions per minute. The envelope method was specifically used to demonstrate monitoring effectiveness with the created Lucia software. By synchronizing the monitoring process, it is possible, with an accuracy of less than $0.1 \%$, to identify increasing failures in the parts of the electric drive. The experimental process can be shown in the example of the bearing with the damaged inner ring. The estimated frequencies arising from damage, depending on the rotational speed for a roller bearing type 6006 at a given shaft rotation speed, is $27.1 \mathrm{~Hz}$. As the laboratory has an etalon (specifically designed according to standards) bearing with damaged inner rings, this particular prototype with damage on the inner ring was chosen to calculate the accuracy of diagnostics of the rolling bearing condition. The inner ring failure response frequency at a shaft speed of $300 \mathrm{rpm}$ is $27.1 \mathrm{~Hz}$. 
The original raw data containing the failure responses in the inner ring of the studied bearing can be visualized in the spectrum. This bearing has not been operated, and, therefore, it has been selected as the initial working standard with a known failure pattern. The raw data are presented in the time domain, as shown in Figure 10.

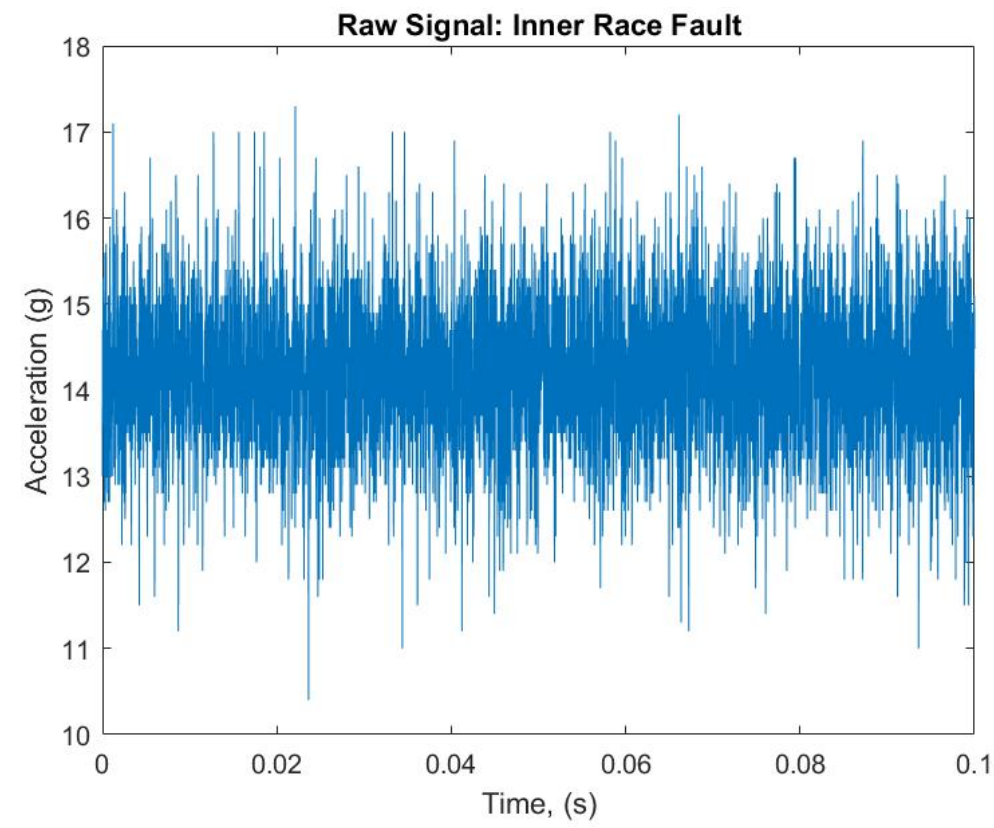

Figure 10. Raw signal of broken inner ring in time domain.

The motor shaft speed is $300 \mathrm{rpm}$. At this frequency, it is difficult to detect failures of the rolling bearing. In Figure 11, a visualization of the same original raw data in the frequency domain is presented.

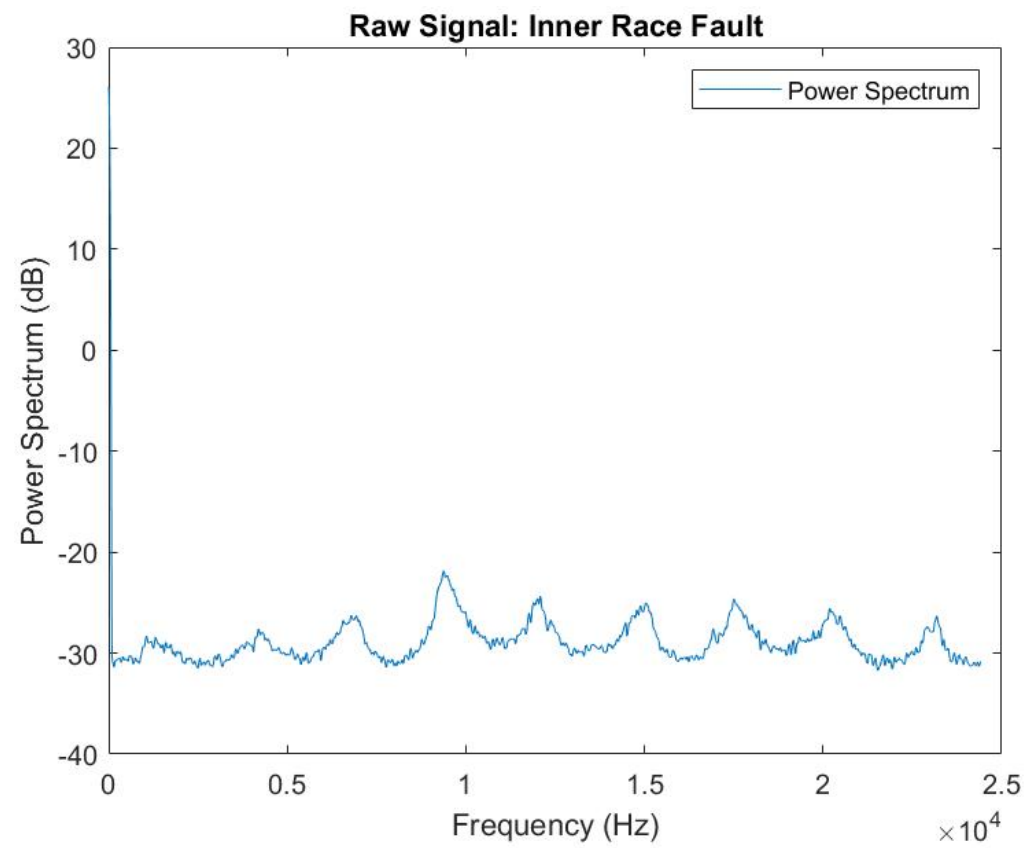

Figure 11. Raw signal of the damaged inner ring in frequency domain.

Figure 12 presents the power spectrum of the unprocessed signal in the low-frequency region. On an enlarged scale, it is possible to study the amplitude-frequency vibration spectrum of the acceleration envelope in the rolling bearing with defects on the inner ring. 


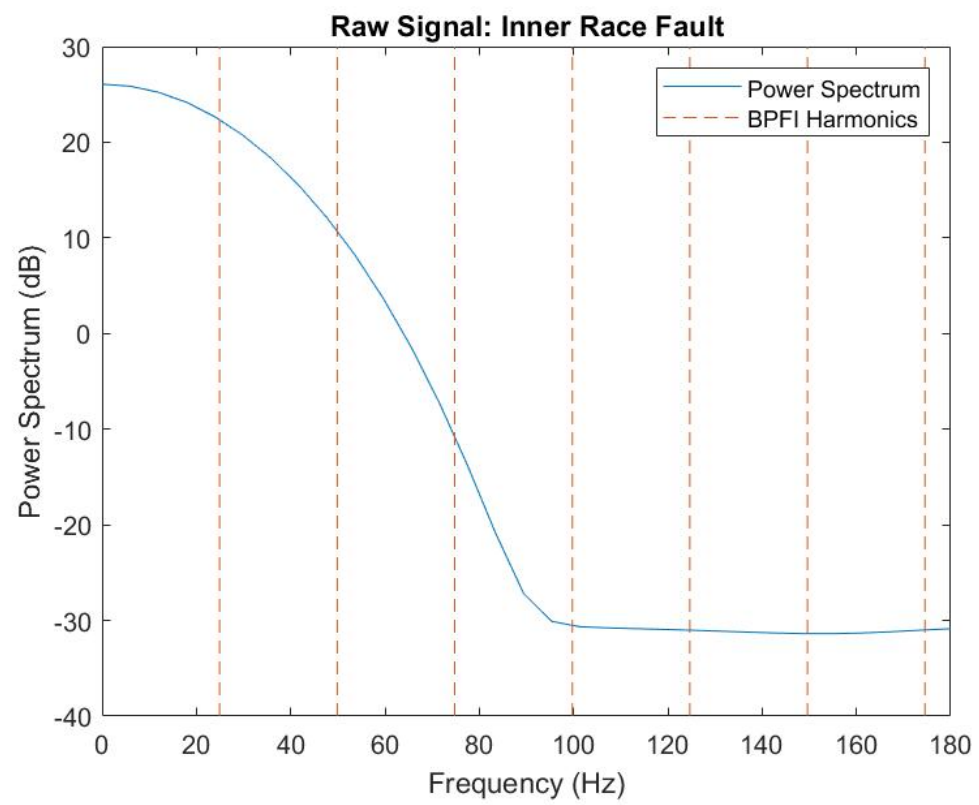

Figure 12. Power spectrum of raw signal.

Time-frequency analysis of the raw signal does not accurately distribute the energy over frequency intervals for any partitioning of the frequency domain. At the frequency response, the modulation frequency can be observed at about $1 /(0.055-0.0046)=111 \mathrm{~Hz}$. It indicates that the bearing has a potential problem in the inner ring, as shown in Figure 13. In the graph, the horizontal arrow shows the time interval in order to determine the likelihood of detecting a potential damage in the inner ring of the bearing.
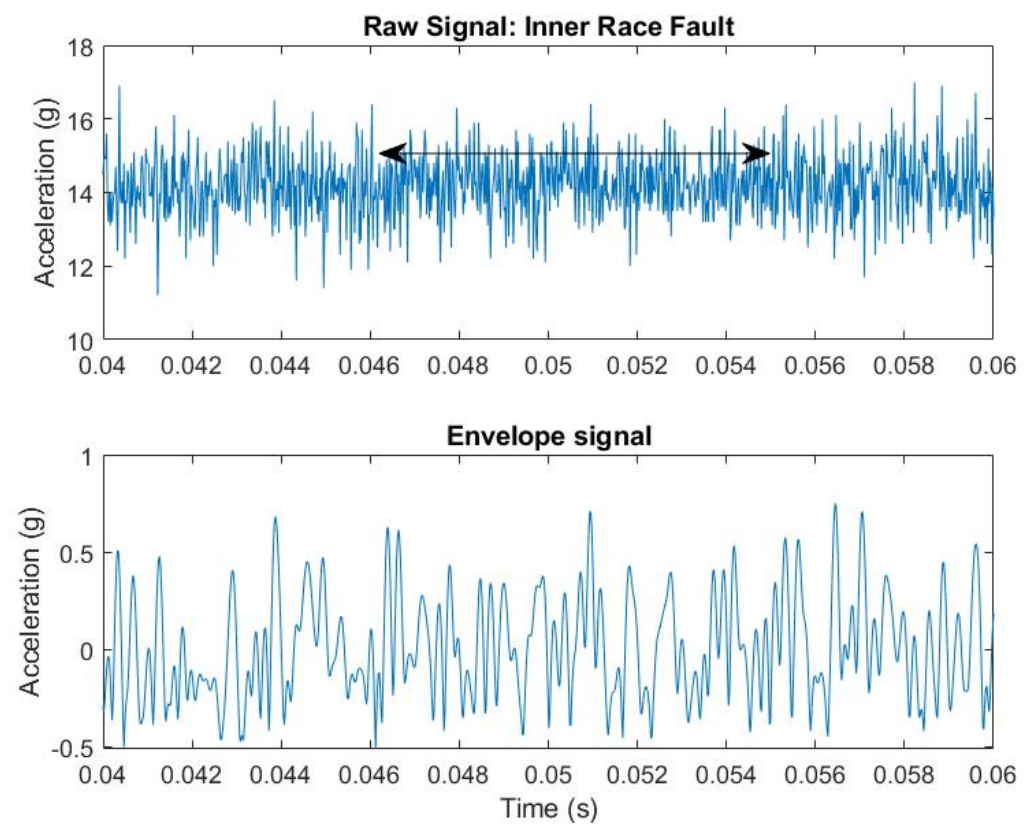

Figure 13. Power spectrum of raw signal.

A similar method and vibration diagnostics with different signal transmission rates and intervals between signals were carried out for the etalon bearing with known damage on the inner ring and the bearing with expected damage on the inner ring. The information transfer rate was correlated with the intervals between the signals and varied from five measurements per second to 20 measurements per second. The intervals between the signals ranged from 70 milliseconds to 400 milliseconds. The results are shown in Figure 14, 
where the spectrum of the acceleration envelope of a rolling bearing with defects in the inner rings presents a failure response frequency at $27.0182 \mathrm{~Hz}$.

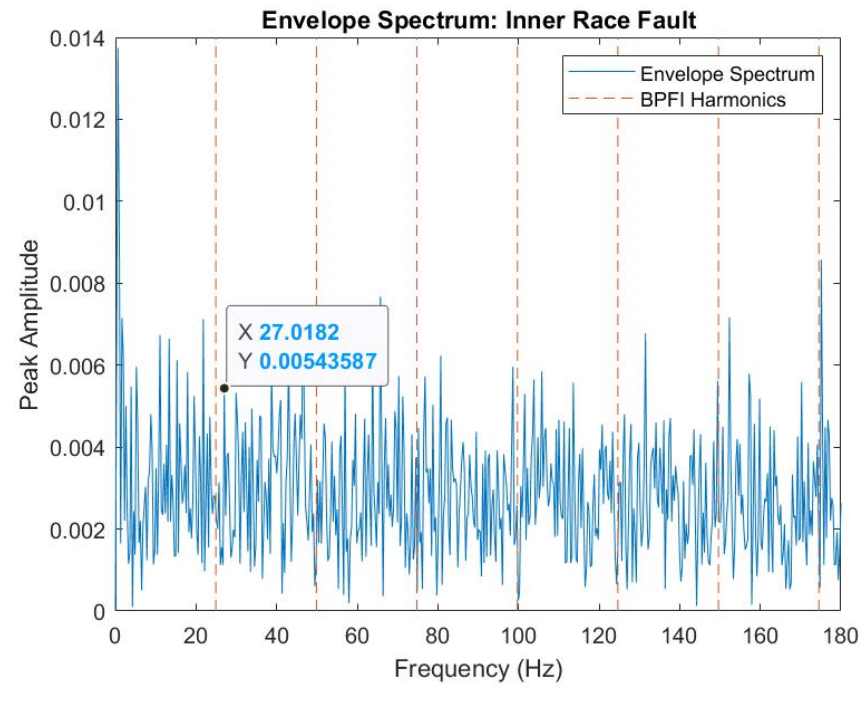

(a)

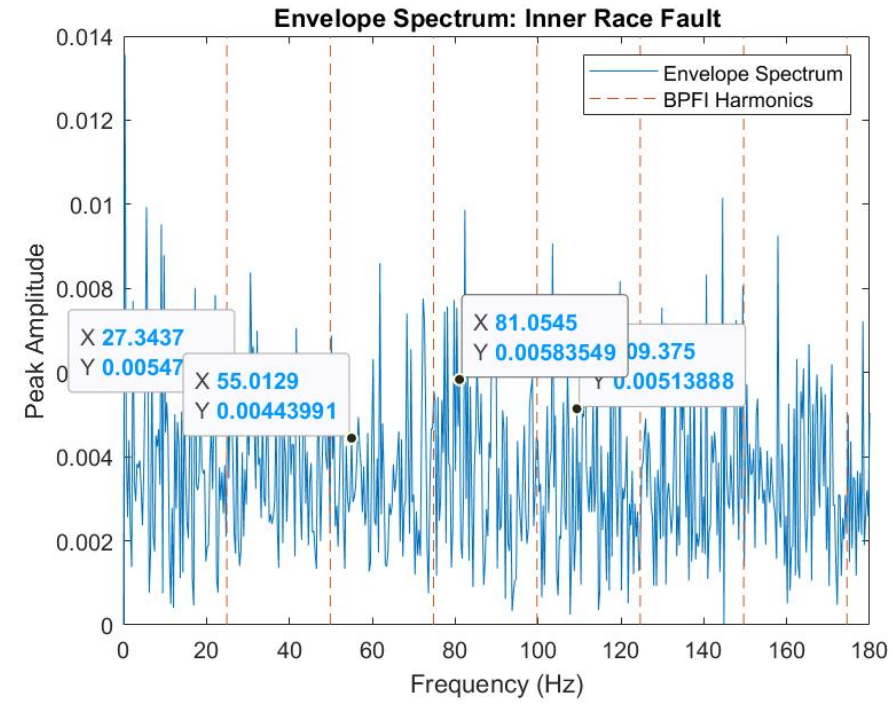

(b)

Figure 14. Acceleration envelop of a rolling bearing with damaged inner ring: (a) etalon bearing and (b) experimental bearing.

The accuracy of conducted experiments is presented in Table 1. According to the calculations of the metrological characteristics of the measurement system, the error in transmitting signal information over communication lines is $\pm 1 \mathrm{~ms}$.

Table 1. Measurement uncertainty and comparison of diagnostic results of an etalon bearing and experimental bearing with damaged inner ring.

\begin{tabular}{cccccc}
\hline Input Value & $\begin{array}{c}\text { Estimation of the } \\
\text { Input Value, Hz }\end{array}$ & $\begin{array}{c}\text { Standard } \\
\text { Uncertainty, Hz }\end{array}$ & $\begin{array}{c}\text { Number of Degrees } \\
\text { of Freedom }\end{array}$ & $\begin{array}{c}\text { Sensitivity } \\
\text { Coefficient }\end{array}$ & $\begin{array}{c}\text { The Contribution } \\
\text { of Uncertainty }\end{array}$ \\
\hline \multirow{2}{*}{$\mathrm{F}_{\mathrm{S}}$} & 27.0182 & 0.83 & 4 & -1 & -1 \\
$-\mathrm{u}_{\mathrm{A}}\left(\overline{\mathrm{F}}_{\mathrm{S}}\right)$ \\
$-\mathrm{u}_{\mathrm{B}}\left(\overline{\mathrm{F}}_{\mathrm{S}}\right)$
\end{tabular}

Figure 15 presents the vibration spectra of a healthy bearing and the bearing with the damaged inner ring. The speed of the motor shaft is presented at the frequency of $5 \mathrm{~Hz}$, while the speed of the damaged V-belt measured at the bearing block for the small belt pulley in the vertical direction is presented at the frequency of $47.5 \mathrm{~Hz}$. The faulty frequency of the bearing can be presented at the frequency of $23.5 \pm 5.7 \mathrm{~Hz}$. Noise pulses are identified here at the rotation frequency of $2 \mathrm{~Hz}$ in both cases. Comparing the frequency spectrum of the healthy bearing to the faulty bearing, the amplitude of the faulty one is significantly higher. The inner ring failure response frequency at a shaft speed of $300 \mathrm{rpm}$ is $27.1 \mathrm{~Hz}$.

Figure 16 present vibration spectra of faulty bearings. In these cases, the speed of the motor shaft is also presented at the frequency of $5 \mathrm{~Hz}$, while the speed of the damaged Vbelt is measured at $47.5 \mathrm{~Hz}$. Faulty frequencies of the bearing are presented at the frequency of $23.5 \pm 5.7 \mathrm{~Hz}$. 


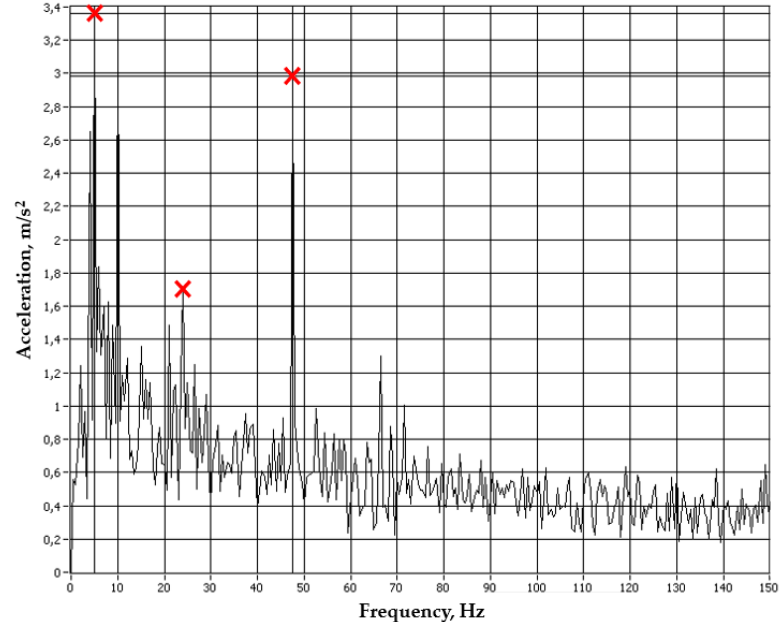

(a)

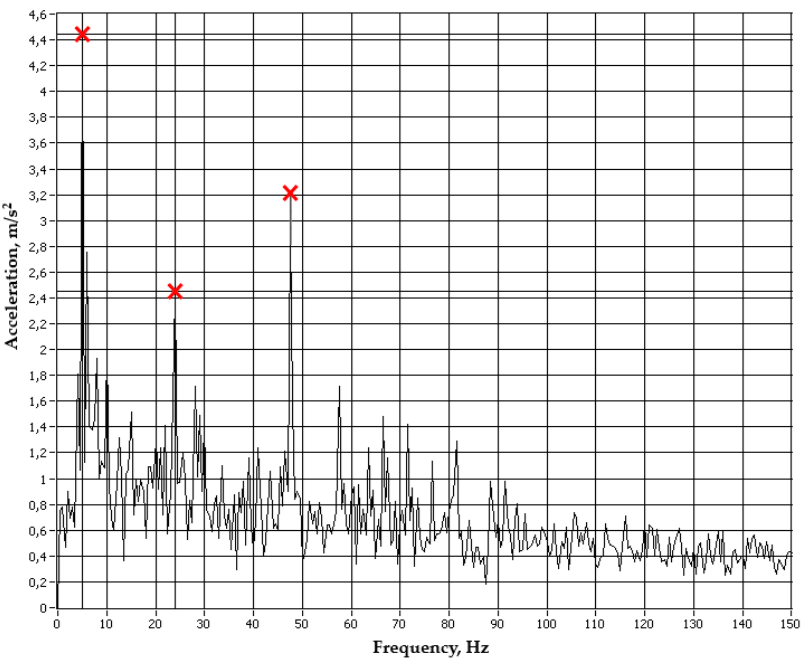

(b)

Figure 15. Comparison of vibration spectra of (a) healthy bearing and (b) bearing with damaged inner ring.

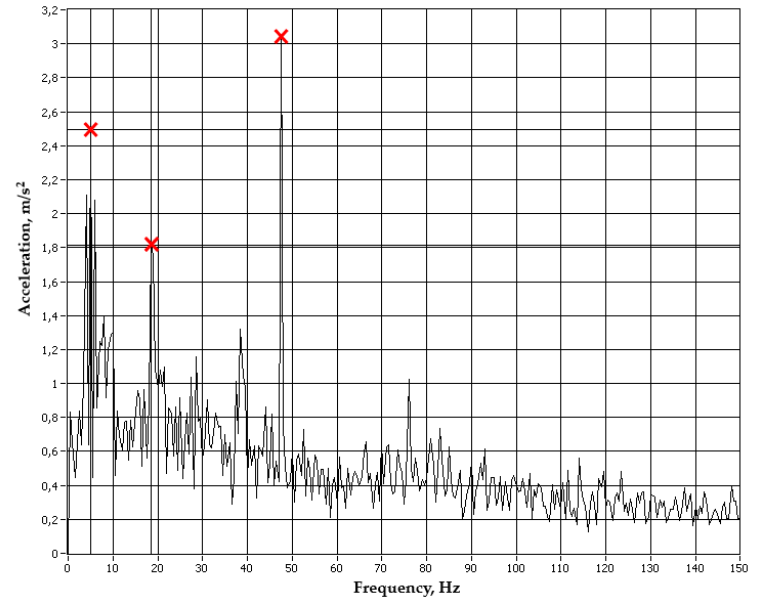

(a)

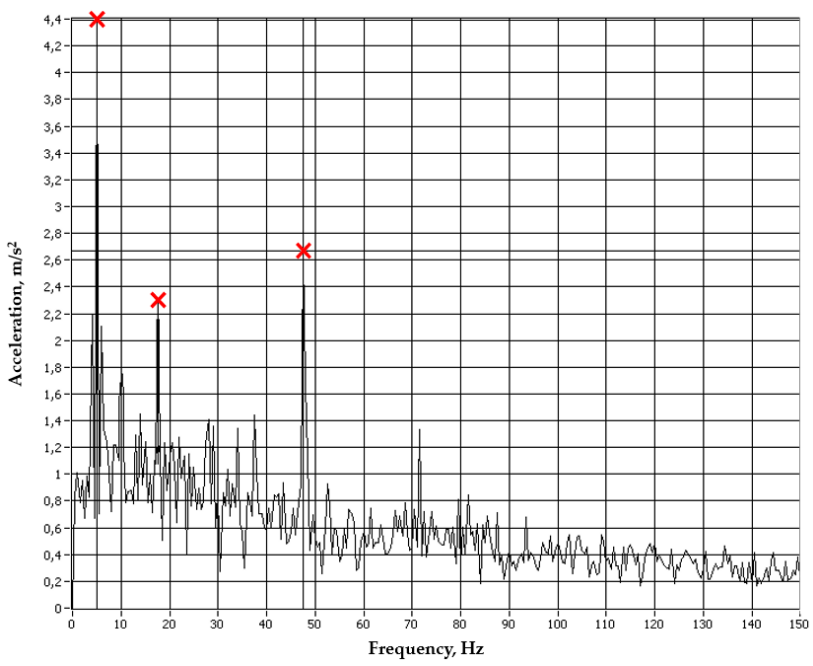

(c)

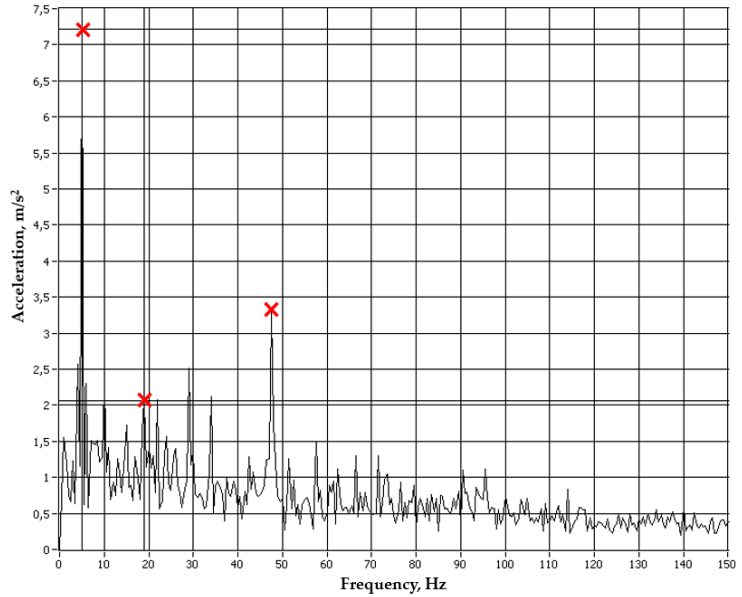

(b)

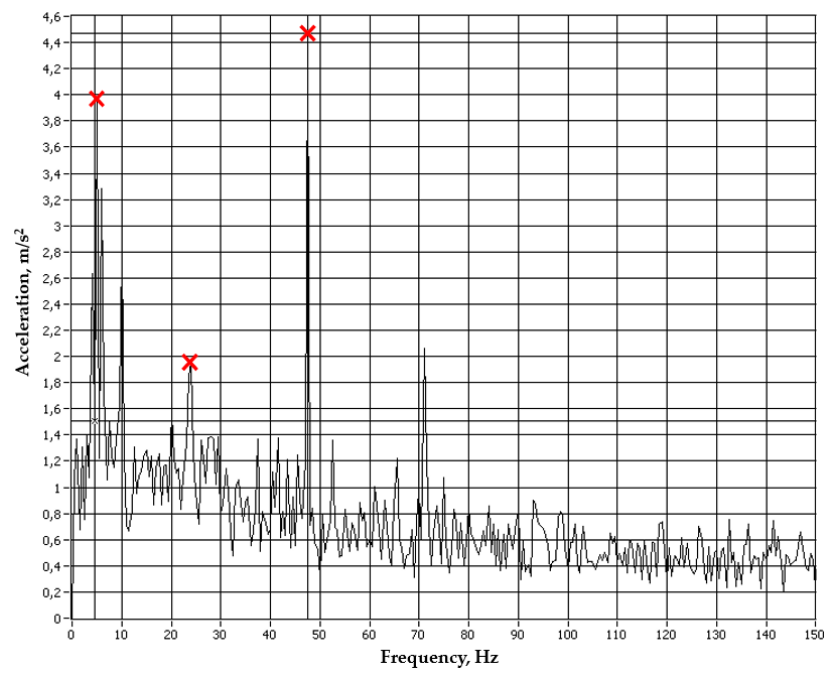

(d)

Figure 16. Vibration spectra of faulty bearings: (a) damaged outer ring, (b) damaged cage, (c) complex damage, and (d) material fatigue. 
The damage frequency of the outer ring is located at $23.5 \mathrm{~Hz}$, which is the fundamental frequency. A higher harmonic component is presented in the case of a damaged cage due to the higher operating asymmetry. In the case of complex fault, harmonic features of the damage are visible but also depend on the fault development stage. The bearing with material fatigue demonstrates higher noise compared to the healthy bearing. The sidebands at the distance of the cage rotation frequency of $2 \mathrm{~Hz}$ are visible.

\section{Conclusions}

The diagnostics of rolling bearings using the proposed method allows us to evaluate the accuracy of the classification of bearing faults. This method is suitable not only for the identification of single defects. The time-frequency method with an accurate data transmission system will also identify multiple bearing failures. The experiments conducted demonstrate that increasing the data transfer rate and reducing the interval between pulses in a real situation increase the accuracy of diagnostics. The effectiveness of the proposed diagnostic program is proven by the example of fault monitoring of both the etalon bearing and the bearing with the expected malfunction on the inner ring, for experimental testing of the program using bearings with multiple defects. This method will cover the entire frequency range of vibration diagnostics, identify defects early, and track their appearance in real-time. The results obtained have a high degree of reliability, at $95 \%$. Thus, the high accuracy of determining time intervals makes it possible to further improve this method's information capacity. Faulty patterns of the experimental bearing can be used for predictive maintenance approaches, which will be considered for future work.

Author Contributions: Conceptualization, K.K. and T.B.; methodology, T.B.; validation, K.K., V.S. and T.V.; formal analysis, A.R.; data curation, T.B.; writing-original draft preparation, K.K.; writingreview and editing, T.V.; visualization, A.R.; supervision, K.K.; project administration, V.S. All authors have read and agreed to the published version of the manuscript.

Funding: This research was funded by [EEA]/[Norway] Grants 2014-2021, "Industrial Internet methods for electrical energy conversion systems monitoring and diagnostics". This research has been also supported by the Estonian Education and Youth Board under grant MINH21084 "Creation of digital training devices for modeling and monitoring of production processes in real-time mode".

Institutional Review Board Statement: Not applicable.

Informed Consent Statement: Not applicable.

Data Availability Statement: Not applicable.

Conflicts of Interest: The authors declare no conflict of interest.

\section{References}

1. Yuan, Y.; Zhao, X.; Fei, J.; Zhao, Y.; Wang, J. Study on Fault Diagnosis of Rolling Bearing Based on Time-Frequency Generalized Dimension. In Shock and Vibration; Hindawi Publishing Corporation: London, UK, 2015.

2. ISO 16063. A Comprehensive set of Vibration and Shock Calibration Standards. In Proceedings of the XVIII Imeko World Congress Metrology for a Sustainable Development, Rio de Janeiro, Brazil, 17-22 September 2006.

3. Huang, H.; Baddour, N.; Liang, M. A method for tachometer-free and resampling-free bearing fault diagnostics under timevarying speed condition. J. Meas. 2019, 134, 101-117. [CrossRef]

4. Caesarendra, W.; Tjahjowidodo, T. A Review of Feature Extraction Methods in Vibration-Based Condition Monitoring and Its Application for Degradation Trend Estimation of Low-Speed Slew Bearing. Machines 2017, 5, 21. [CrossRef]

5. Widodo, A.; Kim, E.Y.; Son, J.-D.; Yang, B.-S.; Tan, A.C.C.; Gu, D.-S.; Choi, B.-K.; Mathew, J. Fault diagnosis of low speed bearing based on relevance vector machine and support vector machine. Expert Syst. Appl. 2009, 36, 7252-7261. [CrossRef]

6. Zheng, L.; Xiang, Y.; Sheng, C. Optimization-based improved kernel extreme learning machine for rolling bearing fault diagnosis. J. Braz. Soc. Mech. Sci. Eng. 2019, 41, 505. [CrossRef]

7. Robert, B.; Randalla, J.A. Rolling element bearing diagnostics-A tutorial. J. Mech. Syst. Signal Process. 2011, 25, 485-520.

8. Ma, S.; Li, S.M.; Xiong, Y.P. Uncertainty Reduced Novelty Detection Approach Applied to Rotating Machinery for Condition Monitoring. J. Shock Vib. 2015, 2015, 737213. [CrossRef] 
9. Ying, Y.; Li, J.; Chen, Z. Study on Rolling Bearing On-Line Health Status Estimation Approach Based on Vibration Signals. In Proceedings of the International Conference on Advanced Hybrid Information Processing, Harbin, China, 17-18 July 2017; pp. 117-129.

10. Yuan, R.; Lv, Y.; Song, G. Fault Diagnosis of Rolling Bearing Based on a Novel Adaptive High-Order Local Projection Denoising Method. Complexity 2018, 2018, 3049318. [CrossRef]

11. Kozochin, M.P.; Sabirov, F.S. Measurement of Spatial Vibrations for Diagnostics of the Performance of a Set of Spindle Assemblies. J. Meas. Technol. 2017, 59, 1310-1315. [CrossRef]

12. Kiselev, M.I.; Komshin, A.S.; Syritskii, A.B. Predicting the Technical State of a Turning Tool on the Basis of Phase-Chronometric Measurement Information. J. Meas. Technol. 2018, 60, 1081-1086. [CrossRef]

13. Komshin, A.S. Mathematical Modelling of Measurement-Computational Monitoring of the Electromechanical Parameters of Turbine units by a Phase-Chronometric Method. J. Meas. Technol. 2013, 56, 850-855. [CrossRef]

14. Syritskii, A.B. Measurement of the Wear of a Cutting Tool by a Phase Chronometer Method in the Course of Working. J. Meas. Technol. 2016, 59, 595-599. [CrossRef]

15. Chen, H.; Jiang, B.; Ding, S.X.; Huang, B. Data-Driven Fault Diagnosis for Traction Systems in High-Speed Trains: A Survey, Challenges, and Perspectives. IEEE Trans. Intell. Transp. Syst. 2020, 1-17. [CrossRef]

16. Rosero, J.A.; Cusido, J.; Garcia, A.; Ortega, J.A.; Romeral, L. Broken bearings and eccentricity fault detection for a permanent magnet synchronous motor. In Proceedings of the IECON 2006-32nd Annual Conference on IEEE Industrial Electronics, Paris, France, 6-10 November 2006; pp. 964-969.

17. Kudelina, K.; Asad, B.; Vaimann, T.; Rassõlkin, A.; Kallaste, A.; Lukichev, D.V. Main Faults and Diagnostic Possibilities of BLDC Motors. In Proceedings of the 2020 27th International Workshop on Electric Drives: MPEI Department of Electric Drives 90th Anniversary (IWED), Moscow, Russia, 27-30 January 2020.

18. Kudelina, K.; Asad, B.; Vaimann, T.; Belahcen, A.; Rassõlkin, A.; Kallaste, A.; Lukichev, D.V. Bearing fault analysis of bldc motor for electric scooter application. Designs 2020, 4, 42. [CrossRef]

19. Kudelina, K.; Vaimann, T.; Kallaste, A.; Asad, B.; Demidova, G. Induction Motor Bearing Currents-Causes and Damages. In Proceedings of the 2021 28th International Workshop on Electric Drives: Improving Reliability of Electric Drives (IWED), Moscow, Russia, 27-29 January 2021.

20. JCGM 100:2008; Evaluation of Measurement Data-Guide to the Expression of Uncertainty in Measurement. JCGM, 2008; 120. Available online: https:/ / www.accredia.it/en/documento/jcgm-1002008-evaluation-of-measurement-data-guide-to-theexpression-of-uncertainty-in-measurement/(accessed on 22 December 2021). 